Revista de Antropología y Filosofía de lo Sagrado

\title{
ENTRE LOS KAMIY LOS EMPERADORES -UN ANÁLISIS HISTORIOGRÁFICO DE LA RELACIÓN ENTRE LA ARQUEOLOGÍA Y LA MITOLOGÍA EN EL JAPÓN MODERNO-
}

\section{BETWEEN THE KAMI AND THE EMPERORS -A HIS- TORIOGRAPHIC ANALYSIS OF THE LATIONSHIP BETWEEN ARCHAEOLOGY AND MYTHOLOGY IN MODERN JAPAN-}

\author{
Rafael Abad de los Santos ${ }^{1}$ \\ Universidad de Sevilla (España)
}

Resumen: Este trabajo tiene como objetivo básico analizar las relaciones entre la arqueología, disciplina que se institucionaliza en Japón durante el período Meiji (1868-1912), y el conjunto de relatos definido como "mitología japonesa". Como se discute en este artículo, la arqueología japonesa estableció desde sus orígenes dos espacios discursivos, uno creado exclusivamente a partir del conocimiento arqueológico, y otro, de carácter mito-histórico, que se apoyaba en las crónicas compiladas por el poder político durante la Antigüedad. Los estudios mitológicos en un sentido estricto surgen en Japón a principios del siglo XX, una época en la que el nuevo Estado Meiji ya había incorporado el relato mítico a la enseñanza de la historia japonesa. Ante el uso político de esta narrativa, la comunidad arqueológica nipona no constituirá un ente monolítico, variando sus reacciones entre el revisionismo, un ferviente colaboracionismo, y el silencio.

Palabras clave: Arqueología Japonesa - Mitología Japonesa Mito-historia - Kojiki - Nihon Shoki

[1] (rafabadel@us.es) Profesor del Área de Estudios de Asia Oriental (Departamento de Filologías Integradas) de la Universidad de Sevilla. Licenciado en Historia (Universidad de Sevilla, 2001) y Doctor en Humanidades (Universidad de Hokkaido, 2009), ha sido becario del Ministerio de Educación Japonés (Hokkaido, 2002-2009), Postdoctoral Researcher (Hokkaido, 2009-2010) y Fellowship Researcher de la Fundación Japón (Tokushima, 2013). Sus principales líneas de investigación se centran en la Prehistoria y Protohistoria del archipiélago japonés, la historia de la arqueología y la antropología en el Asia Oriental,y el desarrollo de las teorías etnogenéticas en el Japón moderno. 
Abstract: This paper analyze the relations between archaeology,
a discipline that was institutionalized in Japan during the Meiji period (1868-1912), and the collected stories defined as "Japanese mythology". As discussed here, Japanese archaeology established from its origins two discursive spaces, one created exclusively from archaeological knowledge, and another, of myth-historical character, which relied on the chronicles compiled by political power during antiquity. Mythological studies in a strict sense arise in Japan at the beginning of the 20th century, a time when the new Meiji State had already incorporated the mythical stories into the teaching of Japanese history. Given the political use of this narrative, the Japanese archaeological community will not constitute a monolithic entity, varying its reactions between revisionism, fervent collaborationism, and silence.

Keywords: Japanese archaeology - Japanese mythology Myth-history - Kojiki-Nihon Shoki

\section{Introducción}

La relación entre la mitología y el mundo académico en Japón ha constituido, desde el inicio del proceso de modernización iniciado con la Restauración Meiji (1868), un territorio complejo, en donde especialmente la actividad de los arqueólogos nipones, tanto a un nivel teórico como práctico, fue con frecuencia influida, condicionada o directamente restringida por la exégesis que desde el poder se hizo sobre las fuentes fundacionales de la mitología nipona, esto es, el Kojiki y el Nihon Shoki, desde el siglo XIX. En este sentido, un análisis de la relación entre ambos elementos debe tener en cuenta, en primer lugar, que los diferentes relatos, mitos y leyendas que conforman la mitología japonesa fueron re-codificados durante el período Meiji (1868-1912) para construir un relato "histórico" de los orígenes de Japón sobre el que fundamentar la legitimidad de la figura del emperador, que reconquistaba con la Restauración su "autoridad" tras más de dos siglos de poder del clan Tokugawa. Como resultado, la arqueología japonesa, cuyos primeros pasos como disciplina moderna se dan precisamente durante las últimas décadas del siglo XIX, se hallaría desde sus comienzos en una delicada posición, en donde el estudio y la interpretación de los restos materiales descubiertos en el archipiélago hubieron de ajustarse necesariamente a la narración establecida por las cabezas rectoras del nuevo régimen político. Y sin embargo, y como veremos en este artícu- 
lo, tampoco resultaría objetivo o imparcial plantear un escenario en donde los arqueólogos únicamente fueron simples víctimas de las coacciones que ejercía un sistema político despiadado y represivo. En realidad, el vínculo entre la mitología y la arqueología, campo que desde sus orígenes estaba integrado oficialmente dentro del marco académico y museístico creado por el Estado, constituirá una intrincada "alianza" en donde los arqueólogos también desempeñarían en ocasiones un papel proactivo, acorde con las necesidades y demandas de la administración. A lo largo de estas líneas, observaremos como ese nexo nunca respondió a una dinámica monolítica, y que la comunidad arqueológica japonesa tampoco fue un cuerpo homogéneo que reaccionase de un modo uniforme a los requerimientos planteados desde el poder en cada momento.

\section{2. ¿Qué es la "mitología japonesa"?}

Pero ¿qué es la "mitología japonesa" (Nihon shinwa)? Según el Diccionario de Historia Antigua de Japón (Nihon kodaishi kenkyū jiten), generalmente se define como tal al conjunto de historias de carácter mítico que fueron gradualmente compiladas y codificadas por escrito durante los siglos VII y VIII, dando origen a los textos canónicos del Kojiki, el Nihon Shoki y los Fudoki. En ocasiones también se incluyen en ella a poemas contenidos en el Man'yoshü (finales del s. VIII) -la primera antología poética en lengua japonesa-, así como a relatos visibles en otras obras como el Kogoshüi (807) y el Sendai kuji hongi (s. IX), pertenecientes a una época posterior $^{2}$.

El Kojiki, o Records of Ancient Matters tal como fue dado a conocer por la traducción inglesa de B. H. Chamberlain (1850-1935), es la crónica japonesa más antigua que se ha conservado hasta nuestros días. Según su prólogo, fue compilada por el cortesano $\bar{O}$ no Yasumaro (¿?-723), quien la presentaría en la corte a la soberana Genmei (661-721) en el año cinco de la era wadō (712). Mientras, el Nihon Shoki, también llamado Nihongi -Chronicles of Japan en la traducción de W. G. Aston (1841-1911)-, fue concluido sólo ocho años después, siendo el responsable de la recopilación el príncipe Toneri (676-735), quien lo presentó a la misma soberana en el año 720. El considerado tercer pilar de la mitología japonesa está integrado por los Fudoki, término que designa a las descripciones regionales ordenadas compilar por un edicto imperial del año seis de wado (713). En la actualidad sólo se conserva de forma íntegra el Izumo Fudoki, y parcialmente

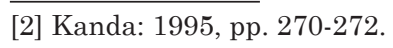


los textos referentes a Hitachi, Harima, Bungo y Bizen, cuyo contenido explica las etimologías de los territorios, sus topografías, características climáticas, productos famosos y tradiciones orales.

Entre todos estos textos, el cuerpo narrativo -o mejor dicho, los cuerpos narrativos, ya que presentan ciertas diferencias- del Kojiki y $\mathrm{Ni}$ hon Shoki conforman la base sobre la que se han desarrollado los estudios mitológicos en Japón a partir del siglo XX. Especialmente el primer volumen del Kojiki y los volúmenes primero y segundo del Nihon Shoki describen el surgimiento y la actividad de los kami $\neg$, o divinidades, desde la creación del universo (tenchi kaibyaku, "separación del cielo y la tierra") hasta su descenso al archipiélago japonés desde el reino celestial y la entronización de Jinmu, el primer emperador, conformando lo que desde la propia Antigüedad fue denominada como la "era de los kami" (kamiyo o jindai). De este modo, en la actualidad al discutir sobre "mitología japonesa", en la mayoría de los casos se está haciendo referencia a los sucesos acontecidos en el transcurso de este "período".

Por cierto, antes de avanzar en el texto, es necesaria una explicación previa respecto a las diferencias en torno al término "mitología" entre las lenguas europeas y la lengua japonesa. En Occidente, la voz "mitología" (del griego $\mu v \theta o \lambda o \gamma i ́ \alpha$ mythología) tiene dos acepciones diferentes y puede hacer referencia tanto al conjunto de mitos de una cultura, sociedad o territorio determinado, como a la disciplina académica que estudia tal conjunto de narraciones. Sin embargo, en japonés se distingue por una parte entre shinwa, término formado por los caracteres shin ("divinidad") y wa ("relato") para referirse a la narrativa protagonizada por las deidades, y por otra, shinwa-gaku, que es la "disciplina" o "discurso" (gaku o logos) que reflexiona sobre tal narrativa. Ambas palabras surgirían en Japón durante la última década del siglo XIX, merced a la traducción de obras occidentales, como las escritas por el lingüista y asiriólogo inglés Archibald Sayce (1845-1933), de modo que, con anterioridad a la difusión de estos términos y conceptos, el Kojiki y el Nihon Shoki eran reconocidos esencialmente como textos sacros por el pensamiento y la teología shintō (kyōgaku). 


\section{La creación del espacio-tiempo arqueológico: la "edad de piedra"}

En el año 1877, el estadounidense Edward Sylvester Morse (18381925), que había sido contratado por el gobierno japonés para impartir zoología y biología en la Universidad de Tokio, lleva a cabo la excavación del conchero de Ōmori (Tokio), considerada generalmente el primer estudio arqueológico moderno en Japón ${ }^{3}$. Aunque durante el período Edo (1603-1867) había florecido una activa corriente de anticuarios, diletantes y coleccionistas de "antigüedades" (kobutsu) -entre las que se incluían lo que hoy llamaríamos "artefactos arqueológicos"-, la excavación de Ōmori supuso un hito tanto por la metodología empleada como por las conclusiones obtenidas por Morse. Así, por ejemplo, la idea de "excavación", esto es, la perforación consciente del suelo retirando la tierra para obtener no sólo objetos "extraños" o "atractivos" desde un punto de vista estético, sino también toda clase de materiales como restos faunísticos, era, simplemente, desconocida en Japón. Pero, sobre todo, el aspecto más impactante de la investigación de Morse radicaría en la explicación que dio sobre los objetos descubiertos en el lugar, entre los que destacaban útiles líticos y grandes cantidades de cerámica: según el zoólogo, estos artefactos, que carecían de paralelos en la cultura histórica japonesa, tenían una antigüedad de miles de años, y demostraban que el archipiélago había sido ocupado originalmente por los portadores de un primitiva cultura en las primeras etapas de la evolución humana, que dependían de la piedra para la elaboración de armas y herramientas, y que no guardaban ninguna relación con sus pobladores modernos ${ }^{4}$. En otras palabras, también en Japón, al igual que en Europa o América, era posible hallar vestigios de una cultura de la Edad de Piedra.

Las palabras de Morse tuvieron un eco inmediato en la sociedad nipona. Por ejemplo, el erudito Kurokawa Mayori (1829-1906), miembro de la escuela de los estudios nativistas (kokugaku), rechazó frontalmente ya en 1879 la hipótesis planteada por el zoólogo, alegando que los japoneses debían haber empleado conjuntamente útiles de piedra y de metal desde el origen de los tiempos, y que en el Kojiki y el Nihon Shoki no existía la menor referencia a una "Edad de Piedra". Según Kurokawa, si los japoneses originalmente desconocían la metalurgia del bronce y del hierro, entonces eran inexplicables los primeros pasajes de estas crónicas, que

[3] Teshigawara: 1994, p. 36-40.

[4] Morse: 1879.

[5] Kurokawa: 1879, p. 1. 
narran, por ejemplo, como Izanagi, una de las divinidades responsables de la creación del archipiélago junto a su hermana-esposa Izanami, mataba a Kawatsuchi -deidad del fuego- usando una espada ${ }^{6}$ en venganza por haber provocado su fallecimiento. Aunque las palabras de Kurokawa no implican necesariamente una interpretación literal del texto escrito, para él era imposible concebir una "historia" de Japón que no se ajustase a lo narrado por las antiguas crónicas, de modo que refutaba el conocimiento arqueológico y la posibilidad de construir un espacio-tiempo alternativo e independiente a partir de las evidencias materiales.

Aunque Kurokawa no modificaría su interpretación en los siguientes años, sin embargo, la actividad del estadounidense fue lo suficientemente poderosa e influyente como para que otros recogiesen el testigo tras su regreso a los Estados Unidos en 1879. Así, en 1884, un grupo de jóvenes universitarios japoneses, que había aceptado la tesis de Morse según la cual Japón fue poblado inicialmente por una "primitiva raza", decidió establecer un "club" dedicado a la discusión sobre descubrimientos arqueológicos y teorías antropológicas sobre los primeros habitantes del archipiélago ${ }^{7}$. Dos años después, este club fue rebautizado oficialmente como la "Sociedad Antropológica de Tokio" (Tōkyō jinrui gakkai), y en un corto espacio de tiempo alcanzó más de 200 miembros, repartidos por todo el país, que se dedicarían a la búsqueda y excavación de yacimientos pertenecientes a la cultura de la Edad de Piedra, denominada ahora "Jōmon" .

Es importante subrayar que esta actividad no se limitó únicamente al trabajo de campo y la recuperación de restos materiales, sino que también estuvo acompañada por aportaciones trascendentales en un sentido teórico y conceptual. Por ejemplo, el historiador y miembro de la sociedad Miyake Yonekichi (1860-1929) manifestaba en la década de 1880 que el pasaje sobre la creación del universo y del archipiélago japonés, tal como era narrado en las antiguas crónicas, debía ser excluido de la educación histórica por su carácter mítico, y en su lugar aplicar los conocimientos arqueológicos y antropológicos disponibles ya en ese momento, aunque fueses escasos. Sin embargo, y al mismo tiempo, Miyake no rechazaba el valor del Kojiki y el Nihon Shoki como fuentes históricas: para él, episodios como el descenso de Izanagi e Izanami desde el puente celestial a la ínsula de Onogoro -la primera isla japonesa- o la venida de Ninigi

[6] Kurokawa: 1888, p. 139. Totsuka no tsurugi significa literalmente una "espada de diez puños", en referencia su longitud (entre 90 y $100 \mathrm{~cm}$.).

[7] Terada: 1975, pp. 31-42.

[8] Literalmente, "motivo" o "patrón de cuerda". Recibe este nombre por las impresiones hechas sobre la superficie de la cerámica con un cordón vegetal cuando todavía no ha sido sometida al proceso de cocción. 
-nieto de la deidad solar Amaterasu, y a su vez bisabuelo de Jinmu- desde Takamagahara a la llanura de Takachiho, desde donde emprendería la conquista del territorio, no eran simple fruto de la imaginación, sino que reflejaban antiquísimos acontecimientos ocurridos en una época en la que no se había difundido todavía la escritura en Japón. En otras palabras, las deidades descritas en las crónicas eran personajes históricos que habían sido gradualmente magnificados y mitificados con el paso del tiempo, y evidenciaban, según Miyake, procesos migratorios desde el continente asiático hacia el archipiélago ${ }^{9}$. De este modo, se identificaba la narrativa de las crónicas como una deformación de la realidad, pero no se rechazaba como una ficción.

La existencia de la cultura de la Edad de Piedra sería reconocida de un modo paulatino por el mundo académico, aunque su "encaje" dentro de los manuales de historia no sería sencillo. Por ejemplo, en el libro de texto redactado por Kamiya Yoshimichi -otro miembro de la sociedad antropológica- y aprobado por el ministerio de Educación en 1891, después de explicar la creación de Japón por Izanagi e Izanami y el descenso de los kami, se introducía un apartado describiendo los útiles y las cerámicas de la Edad de Piedra, pertenecientes a un primitivo pueblo que habitó las islas en "tiempos remotos" o "arcaicos" (taiko), y a continuación se iniciaba el relato perteneciente a la historia de Japón propiamente dicha, que arrancaba con la entronización de Jinmu, el primer emperador ${ }^{10}$. De este modo, se generaba un discurso histórico en donde la aceptación del conocimiento arqueológico no implicaba por sí misma la negación del relato de las antiguas crónicas, sino que ambos coexistían dando lugar a un complejo discurso en el que se entremezclaban sin solución de continuidad un relato mito-histórico y un relato arqueológico. Más allá, esta situación habría de volverse todavía más confusa en las décadas siguientes, a medida que la arqueología afianzaba su posición en el mundo académico pero se veía imposibilitada de construir un modelo histórico propio.

[9] Miyake: 1886, p. 83.

[10] Teshigawara: 2005, pp. 47-49. 


\section{La creación del espacio-tiempo mito-histórico: la "Edad de los kofun"}

Mientras que los restos de cultura de la "Edad de Piedra" iban siendo gradualmente rescatados por todo el archipiélago, existía otro conjunto de estructuras materiales que, en realidad, habían dominado ya el paisaje japonés desde hacía cientos de años: los kofun, túmulos funerarios en cuyo interior se ubican cámaras megalíticas destinadas a albergar los cuerpos de personajes prominentes de las sociedades locales. A lo largo del período Edo, a partir del relato de las antiguas crónicas, muchos de estos túmulos habían sido asociados a miembros concretos de la familia imperial, o directamente a los propios soberanos, incluyendo a personajes que, según un análisis historiográfico actual, pertenecen a un ámbito mítico. Más allá, con el ascenso del pensamiento pro-imperialista (sonnō-ron o sonnō-shisō) durante los últimos años del gobierno Tokugawa, también habría de surgir un corriente que demandaba la reparación de estos "mausoleos imperiales" (tennō-ryō o misasagi), deteriorados por el paso del tiempo, y el esclarecimiento exacto de los difuntos enterrados en cada uno de ellos. En este sentido, es especialmente relevante la llamada "reparación de la era Bunkyü", realizada por el bakufu a propuesta del clan Utsunomiya a principios de la década de 1860, y que supondría no sólo la restauración de más de 100 "mausoleos", sino también la identificación del sepulcro de Jinmu, quien, según la cronología oficial, reinó entre los años 660 y 584 a.C. ${ }^{11}$.

La asociación concreta entre restos materiales y personajes descritos en las antiguas crónicas que hoy consideramos míticos tendría consecuencias determinantes en el posterior desarrollo de los estudios arqueológicos en Japón, al crear un espacio-tiempo en donde no era posible distinguir entre mito e historia, sacralizando así determinados emplazamientos y estructuras materiales cuya administración pasó a depender directamente del ministerio de la Casa Imperial ${ }^{12}$ (kunaishō). Como se ha mencionado anteriormente, desde su creación los miembros de la Sociedad Antropológica de Tokio se entregaron al estudio de los restos de la cultura de la Edad de Piedra. Pero ello no significa que no sintiesen interés y curiosidad por los túmulos y los elementos materiales asociados a ellos, como la cerámica sue ${ }^{13}$, utilizada frecuentemente como ajuar funerario, o

[11] Toike: 2000, pp. 10-39.

[12] Kunaishō o Miyauchi no tsukasa (en la actualidad, Kunaichō).

[13] También llamada iwaibe, es una céramica producida con técnicas originarias de la península de Corea. Es cocida en hornos a altas temperatura, lo cual produce una vitrificación parcial y concede a las piezas un tono gris azulado. 
las figuras haniwa, que se distribuían sobre la superficie de los túmulos y en sus alrededores. Por ejemplo, Tsuboi Shōgorō (1863-1913), quien sería más tarde el primer profesor de antropología de la Universidad Imperial de Tokio, realizó en 1886 la excavación de tres kofun en Ashikaga (prefectura de Tochigi), publicando además un informe en dónde no sólo analizaba las características formales de los túmulos y los artefactos descubiertos en ellos, sino que también especulaba sobre la posible estratificación de las sociedades locales y la existencia de grupos de artesanos divididos según su especialización laboral ${ }^{14}$. Sin embargo, cuenta su discípulo Torii Ryūzō (1870-1952) que, unos meses más tarde, Tsuboi llevó a cabo la excavación de cierto túmulo en la isla de $K y \bar{u} s h \bar{u}$, sin saber que la tumba pertenecía en realidad a la Casa Imperial; cuando la noticia llegó a oídos de la administración, Tsuboi fue duramente advertido (no sabemos por quién, pues Torii no proporciona más detalles) y se le obligó a firmar una declaración jurando que no volvería a acercarse a un mausoleo imperial. Ello le obligaría a mantener en lo sucesivo una actitud conservadora y cautelosa respecto a la excavación de los túmulos, dada su posible vinculación con la familia imperial, hasta su fallecimiento en $1913^{15}$.

Ello no implica, no obstante, que la primera generación de arqueólogos nipones abandonase la investigación sobre los kofun, atemorizada por posibles "represalias" del poder. Al contrario, la Sociedad Arqueológica de Japón (Nippon kōko gakkai), fundada en 1895 por Miyake y Tsuboi, y cuya sede se ubicaba en el Museo Imperial (ahora Museo Nacional de Tokio), fue establecida teniendo como uno de sus principales objetivos el estudio de la cultura material asociada a los túmulos ${ }^{16}$. De este modo, durante el siglo XIX, se organizarían en Japón dos grandes áreas de investigación arqueológica: una, dedicada a la cultura de la Edad de Piedra, y otra, que habría de dirigir sus esfuerzos principalmente hacia el análisis y la clasificación de la cerámica sue, los haniwa y otros artefactos como los objetos de metal descubiertos en los kofun. Mizoguchi define a la primera como una "arqueología segura", que constituía un espacio de libre debate al quedar al margen de cuestiones tales como los orígenes de la casa imperial y la administración de los mausoleos, mientras que la segunda era una "arqueología peligrosa"17.

[14] Teshigawara: 1994, pp. 76-77.

[15] Torii: 1932, p. 4.

[16] Saitō: 1974, pp.121-125.

[17] Mizoguchi: 2006, pp. 65. 
Este dualismo organizativo y metodológico quedaría reflejado de forma manifiesta en Nihon Kōkogaku (1898-1899), el primer compendio arqueológico redactado en lengua japonesa por Yagi Shōzaburō (18661942), miembro de la Sociedad Antropológica y discípulo de Tsuboi. En esta obra, Yagi, basándose en la teoría de Morse y Tsuboi, sostenía que el archipiélago había sido habitado antes de la llegada de los japoneses por un primitivo pueblo de la "Edad de Piedra", cuyos integrantes carecían de los más rudimentarios conocimientos sobre la escritura y, por tanto, habían quedado al margen del registro histórico, pudiendo ser conocidos únicamente a través de las evidencias arqueológicas ${ }^{18}$. En un momento posterior, y cuando los primeros ya habían abandonado las islas, penetrarían en Japón los antecesores de los actuales habitantes, cuyos pasos iniciales podían ser atestiguados no sólo a través del registro material, sino también por medio del contenido de las antiguas crónicas, que, si bien no eran contemporáneas de los hechos que narraban, sí podían ser tomadas como fuentes fidedignas. Así, por ejemplo, Yagi sostenía que el sistema funerario del antiguo Japón había evolucionado a través de tres grandes etapas: la primera, comprendida entre llegada de la pareja prístina Izanami e Izanagi y el primer emperador Jinmu, y caracterizada por sepulcros construidos en lo alto de montañas; la segunda, que abarcaba el período comprendido entre Jinmu y la emperatriz Suiko, durante la cual se erigieron colosales mausoleos circundados por fosos y acompañados por figuras de arcilla (haniwa); y la tercera, desde Suiko hasta las postrimerías del período Nara (710-794), cuando se produjo un declive paulatino que resultó en la desaparición de los kofun ${ }^{19}$ (Yagi 1899). En este caso, la interpretación de las evidencias arqueológicas quedaba supeditada al texto escrito, y se presentaba una línea narrativa ininterrumpida en donde la existencia de figuras "míticas" enlazaba de un modo directo con los miembros del linaje imperial. Se comprendía entonces que el estatus "divino" del emperador era una característica consustancial e inherente, tal como había quedado reflejado en la Constitución Meiji, cuyos primeros artículos insistían en el carácter ininterrumpido del linaje que había reinado Japón desde el origen de los tiempos.

[18] Yagi: 1898, pp. 12-31.

[19] Yagi: 1899, pp. 33-50. 


\section{Deconstrucción y rehistorización del mito: Takagi Toshio y Takahashi Kenji}

En el año 1904 se publica Shōgaku Nihon rekishi, el primer manual de historia japonesa editado tras la promulgación del decreto de designación nacional en 1903, que imponía el uso de un único texto para todo el sistema educativo en el país. Dividido en capítulos protagonizados por "grandes figuras" como método de fácil memorización para el estudiante, la obra iniciaba su relato con la deidad solar Amaterasu y su mandato celestial que exhortaba a su nieto Ninigi a reinar sobre Japón, pasando a continuación a relatar las acciones y hazañas del primer emperador Jinmu, el príncipe Yamato Takeru y la emperatriz Jingū -todos ellos considerados en la actualidad personajes míticos-, y entroncando finalmente con personajes históricos como el emperador Tenchi (626-672) y Fujiwara no Kamatari (614-669) ${ }^{20}$. De este modo, el texto, tomando como única referencia los relatos contenidos en las crónicas imperiales, insistía en la creación de la monarquía japonesa como un proceso unidireccional y sin fisuras, que hundía sus raíces en los albores de la propia historia de Japón. Así, excluía cualquier referencia a la existencia de una "cultura no japonesa" previa a la era de los kami, tal como habían esclarecido las investigaciones arqueológicas desde el descubrimiento del yacimiento de Ōmori por Morse.

Esta narrativa mito-histórica, que gozó de una gran difusión social gracias al sistema educativo, se mantendría vigente hasta la derrota de Japón en la II ${ }^{a}$ Guerra Mundial. Sin embargo, justo en el mismo año en el que se publicaba Shōgaku Nihon Rekishi, salía a la luz Hikaku shinwagaku (Mitología comparada) de Takagi Toshio (1876-1922), obra que puede ser considerada en sentido estricto el punto de partida de los estudios mitológicos en Japón ${ }^{21}$. Influido por autores europeos como Max Müller (1823-1900), Andrew Lang (1844-1912) y Paul Ehrenreich (1855-1914), quienes habrían de poner las bases de los estudios mitológicos comparados en Occidente, Takagi desarrolló una interpretación naturalista de los mitos nipones, afirmando, por ejemplo, que la confrontación entre Amaterasu y su hermano Susanoo podía ser explicada a partir de la racionalización de fenómenos naturales, y que Susanoo, como deidad de la tormenta, era comparable a la deidad védica Indra ${ }^{22}$.

[20] Teshigawara: 2005, pp. 72-73.

[21] Para una breve historia de los estudios mitológicos japoneses, véase Ōbayashi: 1973, pp. 271-285.

[22] Takagi: 1904. 
A lo largo de los siguientes años, Takagi profundizaría este modelo interpretativo, dándolo a conocer en obras como Nihon shinwa monogatari (Cuentos y mitos de Japón, 1911) y Nihon kokumin densetsu (Leyendas de la nación japonesa, 1917). Pronto, eruditos procedentes de otros campos, como el filósofo Inoue Tetsujirō (1856-1944), el especialista en estudios religiosos Anesaki Masaharu (1873-1949) o el historiador Tsuda Sōkichi (1873-1961), se sumarían a Takagi, conformando una corriente heterogénea y ecléctica, cuyo principal logro sería precisamente el reconocimiento sin ambages del carácter mítico de la "era de los kami" tal como había sido plasmada en el Kojiki y el Nihon Shoki. Por ejemplo, Tsuda concluía en su obra Jindaishi no atarashii kenkyū (Un nuevo estudio sobre la historia de la era de los kami, 1913) que el mundo de la "era de los kami" había sido planificado y creado por miembros de la corte ya durante la misma Antigüedad, integrando en un único cuerpo narrativo mitos fundacionales y creencias religiosas con un objetivo político ${ }^{23}$.

Sin embargo, a pesar de esta efervescencia intelectual y académica -Inoue y Tsuda eran profesores de la Universidad Imperial de Tokio, y Anesaki de la Universidad de Waseda-, el mundo arqueológico japonés se mostró aparentemente impermeable a este "revisionismo crítico" que explicaba las divinidades como fenómenos naturales (Takagi), elementos de una cosmogonía primaria (Inoue), o personajes de un discurso político (Tsuda). Por ejemplo, en 1914 el historiador Kita Sadakichi (1871-1939) proponía, acertadamente, que en un sentido cronológico los kofun podían ser divididos a grosso modo en dos grandes etapas. En la primera, la cámara megalítica (sekkan) se disponía en la parte superior del túmulo, y era sólo accesible durante el proceso de construcción, siendo sellada una vez el cuerpo del fallecido había sido dispuesto en su interior; entre los diseños de los túmulos de esta etapa destacaba el kofun de doble montículo, uno cuadrangular y otro circular (zenpō-kōen-fun $)^{24}$, en cuya superficie se distribuían incontables figuras de arcilla (haniwa) en hileras. Por otra parte, los túmulos de la segunda etapa se caracterizaban por un único cuerpo, de planta cuadrangular o circular, en cuyo interior se ubicaban cámaras comunicadas permanentemente con el exterior a través de un corredor o pasillo. Este tipo estaba representado por la tumba del príncipe Shōtoku (574-622) en Shinaga (Osaka), que serviría de modelo para la reglamentación adoptada a partir de la reforma Taika (645), cuyo objetivo era limitar

[23] Tsuda: 1913, p. 244.

[24] Este tipo de kofun recibe en Occidente la denominación de "túmulo con forma de ojo de cerradura". 
derroche de recursos materiales y humanos empleados hasta entonces en la construcción de estas estructuras funerarias ${ }^{25}$.

Frente a esta interpretación, el arqueólogo Takahashi Kenji (18711929), responsable de la sección de historia del Museo Imperial, replicó que el mito de Izanagi, según el cual este accedía al inframundo (yomi no kuni) para buscar a la fallecida Izanami, recorriendo lúgubres y angostas grutas hasta encontrar su cuerpo putrefacto, no era sino una metáfora de la "visita" a una tumba de corredor que permitía comprobar el proceso de descomposición del cadáver. En otras palabras, el mito evidenciaba que los kofun con cámaras de pasillo no pertenecían a una etapa históricamente reciente, como afirmaba Kita, sino que, por el contrario, debían constituir el modelo más antiguo. Del mismo modo, el mito de Ame-no-iwato (o Ama-no-iwato), según el cual Amaterasu se recluye en una cueva tras el enfrentamiento con su hermano Susanoo, sumiendo al mundo en penumbra, también debía reflejar la existencia de cámaras megalíticas accesibles a través de un pasillo horizontal, siendo las cámaras verticales resultado de un diseño posterior ${ }^{26}$. En definitiva, la interpretación del registro arqueológico quedaba supeditada a los relatos del Kojiki y del Nihon Shoki, considerados estos no como una simple "ficción", sino como "historias" que reflejaban hechos, estructuras y detalles reales de una época remota. Esta interpretación sobre el proceso de evolución tipológica de los kofun no empezaría a ser modificada sustancialmente hasta la aparición de Hamada Kōsaku (1881-1938), profesor de la Universidad de Kioto, quien demostraría en las siguientes décadas la validez del planteamiento de Kita, a través del análisis de los ajuares funerarios hallados en los túmulos y la comparación con estructuras funerarias del continente ${ }^{27}$.

[25] Kita: 1914, pp. 1-42.

[26] Takahashi: 1914, pp. 421-428.

[27] Kobayashi: 1971, pp. 58-76. 


\section{Disidencia y discurso oficial: Torii Ryūzō y los "japoneses propios"}

El cuerpo narrativo de las antiguas crónicas no constituía, en ningún caso, un bloque monolítico sin resquicios, que impidiese desde el campo de la arqueología lecturas alternativas al discurso oficial. Un caso paradigmático lo representa la figura de Torii Ryūzō (1870-1953) y su teoría sobre los "japoneses propios" (koyū-Nihonjin) ${ }^{28}$ (Abad 2018). Vinculado desde muy joven a la Sociedad Antropológica y el departamento de Antropología en la Universidad de Tokio, a diferencia de sus colegas Torii desarrolló la mayor parte de sus investigaciones en territorios de ultramar, ya fuesen bien áreas directamente anexionadas por el Imperio en su proceso de expansión colonial (Taiwan, islas Kuriles, península de Corea, etc.), bien zonas próximas (sudoeste de China, Mongolia, etc.). Como resultado, Torii no sólo fue un pionero en el estudio antropológico y arqueológico de estas áreas, sino que además fue capaz de plantear un modelo único sobre los orígenes del pueblo japonés y su cultura, que propuso durante la década de 1910 en su célebre obra El Japón prehistórico (Yūshi izen no Nihon, 1918) y otros textos.

Según él, los primeros habitantes de Japón fueron los ainu, que, procedentes del Próximo Oriente, se establecieron en una época remota a lo largo de todo el territorio insular; en otras palabras, los restos de la Edad de Piedra descubiertos por los miembros de la Sociedad Antropológica no eran sino los vestigios que evidenciaban la primera ocupación humana del archipiélago en tiempos prehistóricos. A continuación, un segundo proceso migratorio llevó a las islas desde el septentrión asiático a grupos mongoloides, que, al igual que los ainu, desconocían la escritura, pero cuya cultura material presentaba un aspecto propio e inconfundible: frente a la plasticidad y el barroquismo de las vasijas de los primeros -la cerámica $J \bar{o}$ mon-, la cerámica de los llamados por Torii "japoneses propios" (koyu-Nihonjin) estaba caracterizada por superficies lisas de tonos claros, junto a motivos decorativos geométricos y regulares -la cerámica yayoi-. A estos grupos se unirían posteriormente otros elementos humanos: indonesios, indo-chinos y, nuevamente, poblaciones norasiáticas que pertenecían a la misma estirpe que los "japoneses propios", y que, dotados de un equipo

[28] Abad: 2018. 
material y tecnológico más avanzado, y en comunión con sus "hermanos", lideraron el proceso de unificación que dio origen finalmente a la nación japonesa de época histórica. En el núcleo de este grupo se encontraban los fundadores de la casa imperial ${ }^{29}$.

Este modelo explicativo, partiendo de las ideas imperantes en el período Meiji, como el origen multiétnico del pueblo japonés y el "paradigma de la sustitución" ${ }^{30}$, incorporaba al mismo tiempo el conocimiento arqueológico más novedoso en aquel momento, e insistía en que dos primitivas culturas -y no sola una, como se afirmaba hasta entonces-, se habían asentado y desarrollado originalmente en el archipiélago. Pero, sobre todo, es necesario destacar aquí que, según Torii, aunque los "japoneses propios" pertenecían a un tiempo anterior a la aparición de la escritura y del registro histórico, sin embargo, la memoria de su existencia podía rastrearse no sólo a través del registro arqueológico sino también a partir de la lectura de las antiguas crónicas: en concreto, los "japoneses propios" se correspondían con los denominados Kuni-tsu-kami, esto es, las "divinidades de la tierra", como Ashinazuchi y Tenazuchi, cuya hija Kushi-nada-hime se convirtió en esposa de Susanoo, o Ōyamatsumi, que Ninigi y otras "deidades celestiales" (Ama-tsu-kami) se encontraron tras descender desde Takamagahara cuando iniciaron la conquista y unificación del país. De este modo, se establecía un vínculo positivo entre restos arqueológicos -la llamada luego cultura Yayoi- y personajes descritos en los textos, que eran interpretados como los líderes originales de las primeras comunidades de "japoneses", en un sentido estricto, asentados en el territorio.

Publicado originalmente en 1918, El Japón prehistórico se convirtió rápidamente en un best seller en la sociedad japonesa del período Taishō, alcanzando nueve ediciones en poco más de tres años, a las que seguiría luego una edición ampliada en $1925^{31}$. Avalado por su prestigio académico y social, Torii propuso entonces reformar los manuales de historia empleados en la educación básica, que afirmaban que los antepasados de los japoneses habían penetrado en el archipiélago en una época relativamente reciente, siendo portadores ya de una avanzada cultura caracterizada por

[29] Torii: 1918.

[30] Sakano: 2005, pp. 76-83.

[31] Saitō: 1984, p. 581. 
la escritura, la agricultura del arroz, la metalurgia y la construcción de colosales mausoleos. Frente a ello, defendió que el modo de vida de los "japoneses propios" se había basado en la caza, la pesca y la recolección de alimentos, siendo la cerámica yayoi y las herramientas de piedra halladas junto a esta la expresión material de su cultura ${ }^{32}$.

Torii no estaba vinculado a los círculos historiográficos marxistas que habían empezado a florecer en Japón, especialmente tras la I ${ }^{a}$ Guerra Mundial y la Revolución Rusa de $1917^{33}$, y su interpretación de las "divinidades de la tierra" como ascendientes del emperador conducía, consciente o inconscientemente, a legitimar la posición de la casa imperial, proyectando su vínculo con el archipiélago en un pasado prehistórico. Sin embargo, la idea de que los primeros japoneses habían sido cazadores y pescadores en las etapas iniciales del progreso humano, incapaces de obtener el alimento a través del cultivo del arroz e ignorantes de la tecnología necesaria para elaborar útiles de metal, era difícilmente aceptable para el Ministerio de Educación, cuyas directrices para la enseñanza histórica seguían estando dictaminadas bajo el gran lema de la Restauración Meiji "Civilización e Ilustración" (bunmei kaika). Por ello, los responsables del Ministerio sólo mostrarían la más absoluta de las indiferencias ante los razonamientos de Torii, que no volvió a insistir luego en su crítica a los manuales de historia ${ }^{34}$.

\section{Epílogo: declive y resurrección del mito}

En el año 1935, el gobierno japonés establecía una comisión para identificar los "lugares sacros" (seiseki) relacionados con el primer emperador Jinmu durante su conquista de Japón, como uno de los pasos preliminares para la celebración del 2.600 aniversario del nacimiento de la monarquía japonesa en 1940. Ninguno de los historiadores que formaban parte de la comisión -entre los que se encontraban figuras clave de la historiografía nipona como Tsuji Zennosuke (1877-1955) o Hiraizumi Kiyoshi (1895-1984)- consideraba a Jinmu como una figura realmente histórica,

[32] Torii: 1924, pp. 131-138.

[33] Gayle: 2014, pp. 216-217.

[34] Harunari: 2003, pp.19-30. 
pero compelidos por las circunstancias y en un creciente clima de exaltación militarista, todos aceptaron sus conclusiones ${ }^{35}$; ello conduciría al cenit del proceso de historización del cuerpo narrativo del Kojiki y el Nihon Shoki. Por su parte, la comunidad arqueológica japonesa quedó dividida entonces entre los que respaldaban explícitamente el discurso imperialista, como Gotō Shuichi (1888-1960), y aquellos otros que optaron por un silencio pragmático, como Umehara Sueji (1893-1983) o Yamanouchi Sugao $(1902-1970)^{36}$.

Lógicamente, la derrota definitiva de las tropas imperiales en 1945 ante los Estados Unidos de América produjo un drástico reajuste de la arqueología japonesa en todas sus dimensiones. En primer lugar, la pérdida de los territorios de ultramar supuso el fin del trabajo de campo de decenas de especialistas, que se vieron obligados a regresar a la metrópoli y hacerse un sitio en la nueva organización académica y profesional que surgía entonces. Pero, sobre todo, las consecuencias de la derrota serían especialmente profundas desde una perspectiva intelectual, pues el desmantelamiento del régimen ultranacionalista y militarista implicó la disolución de la exégesis ideologizada que había sido impuesta sobre la enseñanza de la historia desde el período Meiji. Como resultado, durante los primeros años de la posguerra se materializó una nueva historia de Japón, "científica", "empírica" y "factual", en donde los primeros episodios de esta estarían fundamentados exclusivamente en el conocimiento arqueológico y antropológico. Precisamente en el año 1946, Aizawa Tadahiro (1926-1989) descubría el yacimiento de Iwajuku en la prefectura de Gunma, demostrando que el archipiélago fue refugio de cazadores paleolíticos, y la ocupación humana de este se remontaba a decenas de miles de años ${ }^{37}$.

Dentro de este "modelo aséptico" de la historia de Japón, la referencia a las antiguas crónicas fue totalmente desterrada. Como señalase Mori Köichi (1928-2013), mencionar las palabras "Kojiki" y "Nihon Shoki" especialmente en las décadas de 1950 y 1960 era motivo suficiente para que alguien fuese calificado de "no científico" (hi-kagaku-teki), granjeándose el desprecio de la comunidad académica ${ }^{38}$. Fruto de ello, tras la II Gue-

[35] Brownlee: 1997, pp. 182-185.

[36] Harunari: 2003, pp.191-210, 219-222.

[37] Teshigawara: 1994, pp. 201.

[38] Mori: 2005, pp. 13-14. 
rra Mundial surgieron generaciones de estudiantes y jóvenes investigadores que se vanagloriaban de su desconocimiento sobre las fuentes clásicas de la mitología nipona. Habría que esperar a la década de 1980 para que nuevos aires renovasen este ambiente: en 1984, se descubrió en Kōjindani (prefectura de Shimane, en el extremo meridional de la isla de Honshū) un depósito formado por más de 350 espadas de bronce del período Yayoi, dispuestas cuidadosamente, junto a objetos campaniformes y alabardas, evidenciando que el lugar había sido un centro siderúrgico y tecnológico, y más allá, ceremonial, hacía más de dos mil años. En realidad, la mitad oriental de Shimane, en donde se ubica Kōjindani, se corresponde con la antigua región de Izumo, que, según la tradición, había sido el escenario del llamado kuni-yuzuri, esto es, la "transferencia de la tierra", en virtud de la cual los Kuni-tsu-kami delegaron el gobierno de Japón a las divinidades celestiales. En otras palabras, la trascendencia de la que gozaba Izumo en el relato mítico de las fuentes escritas, a los ojos de muchas personas, podía ser corroborada de alguna forma a través del registro material, y ello, cuatro décadas después del desenlace de la contienda, obligaba a replantear una "nueva" relación entre la arqueología y las fuentes escritas, liberadas ya del yugo ideológico que había impregnado y dominado su lectura hasta 1945. En realidad, esta exégesis, como si de un péndulo se tratase, volvía a insistir en la idea del mito como memoria o vestigio de acontecimientos pasados, y no como simple relato imaginado. De este modo, se plantaba de nuevo la semilla para el debate sobre la verdadera naturaleza del mito en el Japón del siglo XXI. 


\section{Bibliografía}

Abad de los Santos, Rafael (2018) "Torii Ryuzo y el discurso etnogenético en el Japón Taisho", en Delgado Algarra, Emilio (ed.) Historia, Educación Plurilingüe y Enseñanza de las Ciencias Sociales en el Contexto Hispano-japonés, Huelva: Servicio de Publicaciones de la Universidad de Huelva.

Brownlee, John S. (1997) Japanese Historians and the National Myths, 1600-1945: The Age of the Gods and Emperor Jinmu, Vancouver: UBC Press.

Gayle, Curtis A. (2014) "The World of Modern Japanese Historiography: Tribulations and Transformations in Historical Approaches", en Duara, P. et al (eds.) A Companion to Global Historical Thought (Wiley Blackwell Companions to World History), Oxford: Wiley-Blackwell.

Harunari, Hideji (2003) Kōkogakusha wa dō iKita ka - kōkogaku to shakai, Tokio: Gakuseisha.

Kanda, Norishiro (1995) "Nihon shinwa", en Abe, T. et al. (eds.) Nihon kodaishi kenkyū jiten, Tokio: Tōkyōdō Shuppan.

Kita, Sadakichi (1913) "Jōko no ryōbo - taiko yori Nara chō ni itaru”, Kōryō. Tokio: Nihon rekishi chiri gakkai.

Kobayashi, Yukio (1971) "Kofun bunka hennen ron", en Ronshü Nihon bunka no kigen 1 - kōkogaku, Tokio: Heibonsha.

Kurokawa, Mayori (1879) "Jōdai sekki kō”, Hakubutsu sōsho, vol. 2, Tokio: Naimushō hakubutsu kyoku.

Kurokawa, Mayori (1888) Zōtei kōgei shiryō, Tokio: Yurindō.

Miyake, Yonekichi (1886) Nihon shigaku teiyō, Tokio: Fukyūsha.

Mizoguchi, Koji (2006) Archaeology, Society and Identity in Modern Japan, Cambridge: Cambridge University Press.

Mori, Kōichi (2005) Kiki no kōkogaku, Tokio: Asahi bunko.

Morse, Edward S. (1879) "Shell mounds of Omori", Memoirs of the Science Department. University of Tokio, Japan, vol. I, part I.

Ōbayashi, Taryō (1973) Nihon shinwa no kigen, Tokio: Kadokawa sensho. 

bumi kan.

Saitō, Tadashi (1974) Nihon kōkogaku shi, Tokio: Yoshikawa hiro-

Saitō, Tadashi (1984) Nihon kōkogaku shi jiten, Tokio: Tōkyōdō shuppan. shobō.

Sakano, Tōru (2005) Teikoku Nihon to jinruigakusha, Tokio: Keisō

Takagi, Toshio (1904) "Hikaku shinwagaku", Teikoku hyakka zansho, vol. 116, Tokio: Hakubunkan.

Takahashi, Kenji (1914) "Kita hakase no jōko no ryōbo wo yomu", Kokogaku zasshi, vol. 4, $\mathrm{n}^{\circ} 7$.

Terada, Kazuo (1975) Nihon no jinruigaku, Tokio: Shisakusha.

Teshigawara, Akira (1994) Nihon kōkogaku no ayumi, Tokio: Meicho shuppan.

Teshigawara, Akira (2005) Rekishi kyōkasho wa kodai wo dō egaitekia ka, ShinNippon shuppansha.

Torii, Ryūzō (1918) Yūshi izen no Nihon, Tokio: Isobe kōyōdō.

Torii, Ryūzō (1924) "Rekishi kyokasho to kunitsukami", Jinruigaku zasshi, vol. 39, $\mathrm{n}^{\circ} 3$.

Torii, Ryūzō (1932) "Kofun no tatari”, Dolmen, vol. 1, nº 4.

Tsuda, Sōkichi (1913) Jindaishi no atarashii kenkyū, Tokio: Nishōdō shoten. Shinbē.

Yagi, Shōzaburō (1898) Nihon kōkogaku (jōkan), Tokio: Kobayashi

Yagi, Shōzaburō (1899) Nihon kōkogaku (gekan), Tokio: Kobayashi Shinbē. 